\title{
Development of Proniosomal Gel: in-vitro, ex-vivo and in-vivo Characterization
}

\author{
Nadeem Ahmed Farooqui ${ }^{1 \star}$, Mousumi Kar², Ravindra Pal Singh ${ }^{3}$, Sanjay Jain ${ }^{4}$ \\ ${ }^{1}$ Department of Pharmaceutics, Suresh Gyan Vihar University, Jaipur, Rajasthan, INDIA. \\ ${ }^{2}$ Department of Pharmaceutics, College of Pharmacy, IPS Academy, Indore, Madhya Pradesh, INDIA. \\ ${ }^{3}$ Department of Pharmaceutics, Indore Institute of Pharmacy, Indore, Madhya Pradesh, INDIA.
}

\begin{abstract}
The aim of the present research work was to characterize the ex-vivo, in-vitro and in-vivo studies of proniosomal (PN) gel of ketorolac tromethamine (KT). Experimental work: Proniosomal suspension was prepared by rotatory flask evaporator with addition of nonionic surfactant (Sodium Cholate) at concentration ranges (3\%, $2 \%$ and $1 \%$ ). Co-solvent like isopropanol, butanol and ethanol as well as dimethyl sulphoxide (DMSO), was later added which act as permeability enhancers in gel formulations. Carbopol 940 was added as the gelling agent in proniosomal suspension. Characterization: PN gel acts as percutaneous enhancers on the transdermal permeability hence were investigated for ex-vivo (Franz Diffusion Cell), in-vitro (Membrane Diffusion Technique) and in-vivo (Estimation of KT in serum at different time intervals by RP-HPLC) studies. Effect of KT on acute inflammation was evaluated in rat carrageenan-induced edema model. Results: Proniosomal gel formulation F1 consisting of sodium cholate, isopropanol and soya lecithin, showed highest drug release of $94.048 \%$ in $24 \mathrm{hrs}$ and formulation F9 showed lowest drug release of $73.789 \%$ in $16 \mathrm{hrs}$. Transdermal flux (J) of formulation F1 was found to be high $\left(7.518 \pm 0.041 \mu \mathrm{g} / \mathrm{cm}^{2} . \mathrm{hr}\right)$ as compared to other formulations and marketed preparation. Proniosomal formulation (F1), consisting of sodium cholate (concentration $3 \%$ ) and cosolvent (isopropanol) attained highest penetrability effect, where sodium cholate and isopropanol induced significant changes in membrane permeability as they completely solubilised membrane phospholipids by sodium cholate micelles. In case of F1 formulation, percent inhibition was found to be $66.84 \%$. Serum estimation of Ketorolac Tromethamine (KT) revealed that application of F1formulation produced 4-fold increase in peak plasma concentration within 12 hours and was maintained upto 24 hours as compared to marketed formulation. Eventually a significant in-vitro-in-vivo correlation was achieved and PN formulation of KT shows significant improvement in bioavailability of KT in systemic circulation when applied via topical route as compared to marketed gel preparation.
\end{abstract}

Key words: Ketorolac Tromethamine, Carbopol 940, Proniosomal Gel, Permeability, inflammation.

\section{INTRODUCTION}

Transdermal delivery of medicaments via skin to the systemic circulation provides suitable route of administration for a variety of drug moiety.

For permeation of drug during transdermal delivery, stratum corneum is the most important layer, which act like as barrier. Various approaches are used of penetration enhancement used to increase the flux through skin membrane. ${ }^{1,2}$ Transdermal drug delivery offers controlled release of the drug; it enables a steady blood level profile, resulting in reduced systemic side effects and patients compliances., ${ }^{3}$ Transdermal drug delivery systems using vesicles based formulation facilitated colloidal particulate carriers such as niosomes or
Submission Date: 10-04-2017; Revision Date: 15-06-2017; Accepted Date: 13-07-2017.

DOI: 10.5530/ijper.51.4.110 Correspondence: Nadeem Farooqui, (Research Scholar in Pharmacy),

Department of Pharmaceutics Suresh Gyan Vihar University, Jaipur, Rajasthan Phone no: 08103172858;

E-mail: nadeemimran2000@ gmail.com; nadeem1712@ rediffmail.com

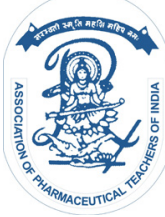

www.ijper.org 
proniosomes have significant advantages over conventional drug delivery system. ${ }^{5,6}$

Proniosomal suspension preparations based on encapsulated drug vesicles which consists of non-ionic surfactants and these vesicles fabricated by dissolving the surfactant in a small amount of a solvent (organic solvent such as ethanol) and aqueous phase (water) and formed semisolid liquid crystal products ..$^{7,8}$

Proniosomal gel prepared from proniosomal suspension which containing a high ratio of solvent/gelling agent. When dispersed in an appropriate solvent, gelling agents form a colloidal network structure. ${ }^{9,10}$ Lipophilic and hydrophilic drugs can be entrapped in proniosomes either in aqueous layer or in vesicular membrane, which produced chemically and physically stable vesicles having low toxicity because of their non-ionic nature.$^{11,12}$

Other advantages incorporate flexibility in their structural constitution, improvement of drug action and prolonged delivery in the stratum corneum and at last proniosomes are biocompatible, biodegradable and non-immunogenic and more stable as compare to other vesicles based formulations. ${ }^{13}$

A Novel NSAID ketorolac tromethamine belongs to pyrrolopyrrole derivatives of nonsteroidal anti-inflammatory drugs. It is a racemic mixture of $[-] \mathrm{S}$ and $[+] \mathrm{R}$ ketorolac tromethamine. Ketorolac tromethamine may be exists in three crystal forms, which are uniformly soluble in water. Oral administration of KT has some prominent side like first pass metabolism, gastric ulceration and renal disease hence to overcome these disadvantages and most enviable formulation would be transdermal gel applied via topical route. ${ }^{14}$

Development of ketorolac tromethamine proniosomal gel has enhanced anti-inflammatory activity, which would indeed be a successful approach and the prepared gels were ex-vivo, in-vitro and in-vivo permeationstudies have been an endeavor to develop gel formulation thus improving patient compliance.

\section{MATERIALS AND METHODS}

\section{Materials}

Soya lecithin, Sodium cholate and Span-80 were purchased from Himedia Chemicals. Dimethyl Sulphoxide,carbopol 940, Potassium dihydrogen phosphate, sodium chloride, and isopropyl alcohol were purchased from Loba Chemie (Mumbai, India); ethanol was purchased from ChangshuYangyuan Chemical (China), and a gift sample of Ketorolac Tromethamine was procured from Piramal Health Care Pvt., Ltd. (Pithampur, India).

\section{FORMULATION}

Preparation of Proniosomal Suspension: - The proniosomes were prepared in various batches by changing surfactants and organic solvents ratio. Proniosomal suspensions were prepared by rotatory flask method by dissolving cholesterol and surfactant in alcohol. Thin film was formed along the sides of the of flask wall. Drug was dissolved in $10 \mathrm{ml}$ of phosphate buffer saline (PBS) solution $\mathrm{pH} 7.4$ and added to thin film for hydration and then sonicated for $5 \mathrm{~min}$. The proniosomal suspension was kept in refrigerator at $4^{\circ} \mathrm{C}$.

Preparation of Proniosomal Gel: - Proniosomal suspension fabricated by thin film hydration method. In optimized formulation (Table 1) of proniosomal suspension (2ml) added carbopol 940 as gelling agent containing glycerin, methylparaben and dimethyl sulphoxide was added as a penetration enhancer then this solution mixed by mechanical stirring and $\mathrm{pH}$ of gel was adjusted by addition of triethanolamine. Proniosomal gel sonicated for 10-15 minutes and kept overnight to eliminate air bubbles. ${ }^{15}$

Formulation of Plain and Placebo Gel: - Plain gel was formulated by using carbopol $940(1 \% \mathrm{w} / \mathrm{v})$ as gelling agent, was allowed to swell in distilled water for 3-4 h. Then drug (20mg) was added into solution, glycerin and methylparaben and dimethyl sulphoxide (DMSO) was added as a penetration enhancer and then mixed solution by mechanical stirring and triethanolamine was added to adjust $\mathrm{pH}$ of gel. Air bubbles were eliminated after sonification keeping gel overnight. Placebo gel was formulated by using carbopol $940(1 \% \mathrm{w} / \mathrm{v})$ as gelling agent, it was allowed to swell in distilled water for 3-4 h and glycerine, methylparaben, dimethyl sulphoxide (DMSO) and triethanolamine was added.

\section{Ex-vivo, In-vitro and In-vivo Characterization of Proniosomal Gel}

Ex-vivo Permeability Study: - Franz diffusion cell was used for skin permeation study with an effective diffusion area of $2.668 \mathrm{~cm}^{2}$. The experiment was carried out using freshly killed goat dorsal skin acquired from the local slaughter house and stored at $18^{\circ} \mathrm{C}$ in the ringer solution. Skin was first flushed with ringer solution at room temperature for $2 \mathrm{hrs}$ with aeration. Then further fat content was removed from subcutaneous tissue of skin by using hand razor. The moisten skin was further wiped with distilled water. A circular piece of skin (about $3.2 \mathrm{~cm}$ diameters) was sandwiched between donor and receptor compartment of the vertical diffusion chamber and $10 \mathrm{mg}$ drug loaded proniosomal gel was added to the mucosal side. The receptor compartment was filled with phosphate buffer $\mathrm{pH} 7.4$, 
kept at constant temperature of $37 \pm 05^{\circ} \mathrm{C}$ and stirred using magnetic stirrer. At appropriate intervals (1, 2, $3,4,5,6,7,8$ to12 hr), $1 \mathrm{ml}$ ofsample was withdrawn from receptor medium and immediately equal volume of fresh receptor solution was added to maintain sink condition of receptor medium. Periodically samples were collected and analyzed by UVspectrophotometer (Shimadzu-1800, Japan) at $322 \mathrm{~nm}$ using phosphate buffer ( $\mathrm{pH}$ 7.4) as blank.

In-vitro Drug Release: - Membrane diffusion technique was used to determine release of ketorolac tromethamine from proniosomal gel. The proniosomal gel equivalent to $10 \mathrm{mg}$ of Ketorolac Tromethamine was positioned in a dialysis bag tied to glass tube acting as adonor compartment. The receptor compartment consists of glass tube, which was placed in abeaker containing $50 \mathrm{ml}$ of phosphate buffer ( $\mathrm{pH}$ 7.4). The lower end of tubecontaining gel was touching the surface of diffusion medium and receptor medium temperature was kept at $37 \pm 05^{\circ} \mathrm{C}$ and was agitated using magnetic stirrer at the speed of $95 \mathrm{rpm}$. Samples were withdrawn periodically. The collected sample was analyzed by UV spectrophotometer.

\section{In-vivo Evaluation}

\section{Animals}

Healthy Wister Rat (150-220gm) and Female Rabbit (2-3 kg) were obtained from animal house, Smriti College of Pharmaceutical Education, Indore, India, and were maintained standard environmental condition (22-280C,$62-70 \%$ relative humidity, 12 -h dark; 12 -h light cycle) and were feed with standard rat and rabbit feed (M/S Hindustan lever Ltd., Bangalore, India) and water ad libitum. The experiment were conducted as per the guidelines of CPCSEA, New Delhi, India (Approval No. IAEC/SCOPE/14-15/100).

\section{Estimation of Ketorolac Tromethamine (KT) by RP-HPLC}

\section{Chromatographic Conditions}

Reverse phase higher pressure liquid chromatographic (RP-HPLC) method was used for estimation of ketorolac tromethamine in formulation. The experimental conditions were optimized on a Shimizu C18 column (250 X $4.6 \mathrm{~mm}, 5 \mu \mathrm{m})$ at ambient temperature using the mobile phase methanol and water with $0.1 \%$ O-Phosphoric acid in the ratio of $60: 40 \mathrm{v} / \mathrm{v}$. it was used as diluents for the preparation and standard solution. The flow rate of mobile phase was set at the rate of $1 \mathrm{ml} / \mathrm{min}$. injection volume was $20 \mu \mathrm{l}{ }^{16-17}$ Proniosomal $(50 \mathrm{mg}$ ) gel was applied to the dorsal surface of rabbit $\left(1.0 \mathrm{~cm}^{2}\right)$. The blood samples $(0.4 \mathrm{ml})$ were taken from the ear vein of rabbit after applying the proniosomal $(50 \mathrm{mg})$ gel at predetermined time $(0,1,2,4,8,12$ and 24 hours). The samples were immediately stored in sterile tubes $(1 \mathrm{ml})$ containing heparin $(0.1 \mathrm{ml})$ and were centrifuged at $2000 \mathrm{rpm}$ for $10 \mathrm{~min}$, and $0.1 \mathrm{ml}$ of the clear supernatant was transferred to another tube. The supernatant was then mixed with equal volume of acetonitrile (for deprotinization) and was again centrifuged at $2000 \mathrm{rpm}$ for $10 \mathrm{~min}$. The clear supernatant (serum) was obtained, transferred to another tube and was kept at $-20^{\circ} \mathrm{C}$ for (RP-HPLC) analysis. (Figure 1)

\section{Pharmacodynamic Study Carrageenan Induced Rat Paw Edema}

Effect of KT on acute inflammation was evaluated in rat carrageenan-induced edema model. Animals were separated into six groups, each group contains four animals. Group -I served as control, Group- II served as negative control whiles the Group- III served as positive control, Group-IV, V and VI received formulations of the PN gel (LCI-1-a, LCI-1-b \& LCE-1-d) 200 mg, respectively. The animals were fasted overnight before experiment and deprived of water during experiment. $0.1 \mathrm{ml}$ of $1 \%$ carrageenan (wt/vol) in normal saline was intradermally injected into the left hind paw of rats. PN gel formulations (LCI-1-a, LCI-1-b, LCE-1-d) and marketed preparation (positive control) were applied topically to the dorsal surface of rats $\left(1.0 \mathrm{~cm}^{2}\right), 30$ minutes before carrageenan injection. Plethysmometer was used to measured paw thickness, before (time 0) and after carrageenan administration, increase in paw thickness was measured at time intervals $1,2,3,4$ and 5 hrs. ${ }^{18-19}$ The percent inhibition was calculated as follows:

$$
\% \text { Inhibition }=\left(\mathrm{Pc}-\mathrm{PT}_{\mathrm{T}} / \mathrm{Pc}\right) \times 100
$$

Where, Pc is the increase in paw thickness of the control group and $\mathrm{P}_{\mathrm{T}}$ is the increase in paw thickness of the treatment groups.

\section{RESULTS AND DISCUSION}

Ex-vivo Permeability Study: - In formulation F1, sodium cholate (concentration 3\%) was attained highest permeability enhancing effect. Sodium cholate was used as surfactant in proniosomal gel formation, which isolates large hydrophobic molecules of skin layers such as proteins and interact with those molecules, which acts as skin barrier, which are then solubilized in the water layer, thus separating membrane. The results of Ex-vivo permeation for F1formulation showed highest permeability 86.048 and F9 showed lowest permeability 42.789 are shown in Figure 1. The flux values of, proniosomal gel (LCI-1-a), LCI-2-b and plain gel were 


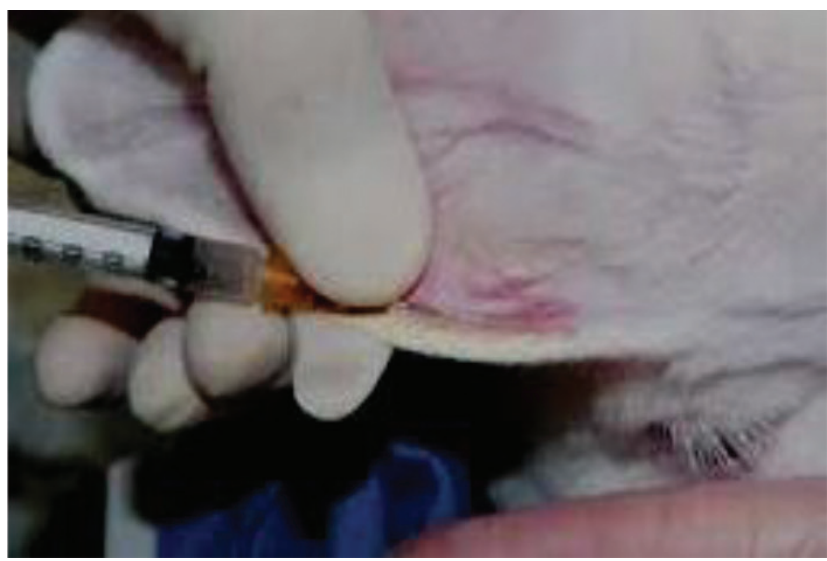

Figure 1: Blood Samples were taken from the Ear Vein of Rabbit.

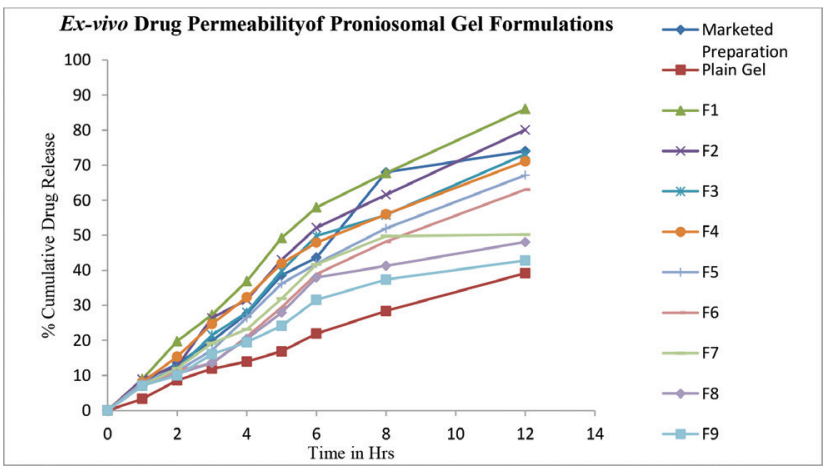

Figure 2: Cumulative Amount of KT Permeated through Goat Skin

found to be $7.518,4.651$ and $2.941 \mu \mathrm{g} / \mathrm{cm}^{2} \mathrm{hr}$ respectively. The Permeability coefficient of proniosomal gel (LCI-1-a), LCI-2-b and plain gel were found to be 3.759, 2.991 and $2.01 \mathrm{~cm} \cdot \mathrm{h}^{-1} \cdot 10^{-3}$. (Table 2 and Figure 2)

In-vitro Drug Release of Proniosomal Gel: - Formulation F1 (LCI-a-1), consists of cholesterol, isopropanol and sodium cholate in the respective ratio $6: 4: 2$,

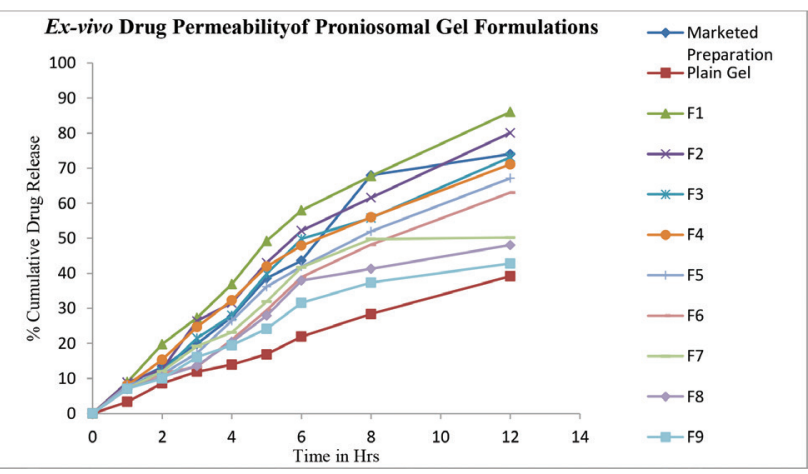

Figure 3: \% Cumulative Drug Release of Gel Formulations

which showed highest drug release of $94.048 \%$ in $24 \mathrm{hrs}$ and formulation F9 showed lowest drug release of $73.789 \%$ in 16 hrs. Soya lecithin was found consisting of unsaturated fatty acids, oleic acid and linoleic acid, and have been reported to show penetration enhancing properties, higher amount of soya lecithin (phospholipids) in proniosomal composition alter the in-vitro drug release as well as influence on formation of vesicles. ${ }^{20,21}$ The structure of carbopol play significant role in drug release. It has been attributed to formation of mechanical layer by the random network of the polymer molecules which further bind and entrap the surrounding water. Subsequently this aqueous phase is the region where the drug diffusion from the gel takes place. (Figure 3)

\section{In-vivo Study}

Serum estimation of Ketorolac Tromethamine (KT) in rabbit was performed by RP-HPLC and data revealed that application of optimized proniosomal gel formulation produced 4-fold higher peak plasma concentration within 12 hours that was maintained over 24 hours also, there is increase in T.max and C.max of drug. These results established the sustained and prolonged delivery of Ketorolac Tromethamine from proniosomal gel

\begin{tabular}{|c|c|c|c|c|c|c|c|c|}
\hline \multicolumn{7}{|c|}{ Table 1: Formulation of Proniosomal Gel } \\
\hline $\begin{array}{c}\text { Batch } \\
\text { No. }\end{array}$ & Formulations & $\begin{array}{c}\text { Proniosomal } \\
\text { Suspension } \\
(\mathbf{m l})\end{array}$ & $\begin{array}{c}\text { Carbopol } \\
\mathbf{9 4 0}(\mathbf{g m})\end{array}$ & $\begin{array}{c}\text { DMSO } \\
(\mathbf{m l})\end{array}$ & $\begin{array}{c}\text { Glycerin } \\
(\mathbf{m l})\end{array}$ & $\begin{array}{c}\text { Methyl } \\
\text { Paraben }\end{array}$ & TEA & Water \\
\hline F1* & LCl-1-a & 4 & 8 & 5 & 1.5 & QS & QS & QS \\
\hline F2 & LCl-2-b & 4 & 8 & 3 & 1.5 & QS & QS & QS \\
\hline F3 & LCl-3-C & 4 & 8 & 2 & 1.5 & QS & QS & QS \\
\hline F4 & LCE-1-d & 4 & 8 & 5 & 1.5 & QS & QS & QS \\
\hline F5 & LCE-2-e & 4 & 8 & 3 & 1.5 & QS & QS & QS \\
\hline F6 & LCE-3-f & 4 & 8 & 2 & 1.5 & QS & QS & QS \\
\hline F7 & LCB-1-g & 4 & 8 & 5 & 1.5 & QS & QS & QS \\
\hline F8 & LCB-2-h & 4 & 8 & 3 & 1.5 & QS & QS & QS \\
\hline F9 & LCB-3-i & 4 & 8 & 2 & 1.5 & QS & QS & QS \\
\hline
\end{tabular}

DMSO: Dimethyl Sulphoxide, TEA: Triethanolamine\& QS Quantity Sufficient. B: Butanol, C: Sodium cholate, E: Ethanol, I: Isopropanol, L: Soya lecithin. 


\begin{tabular}{|c|c|c|}
\hline \multicolumn{3}{|c|}{ Table 2: Permeation Parameters of LCl-1-a, LCl-2-b \& } \\
Plain Gel Formulation
\end{tabular}

Values represented as mean $\pm S D, n=3$

\section{Table 3: Pharmacokinetic Data of In-vivo Drug} Release (KT) in Serum

\begin{tabular}{|c|c|c|c|}
\hline S. No. & $\begin{array}{c}\text { Time } \\
(\mathbf{H r s})\end{array}$ & $\begin{array}{c}\text { Cumulative } \\
\text { Drug Release }(\boldsymbol{\mu g} / \mathbf{m l})\end{array}$ & $\begin{array}{c}\text { Con. Drug Release } \\
(\boldsymbol{\mu} \mathbf{g} / \mathbf{m l})\end{array}$ \\
\hline 1 & 0 & 0 & 0 \\
\hline 2 & 1 & 85 & 85 \\
\hline 3 & 2 & 172 & 87 \\
\hline 4 & 4 & 326 & 154 \\
\hline 5 & $8^{*}$ & 564 & $238^{*}$ \\
\hline 6 & 12 & 755 & 191 \\
\hline 7 & 24 & 929 & 174 \\
\hline
\end{tabular}

$C_{._{\max }}=238(\mu \mathrm{g} / \mathrm{ml})$ and $T_{\text {max }_{\max }}=8 \mathrm{Hrs}$

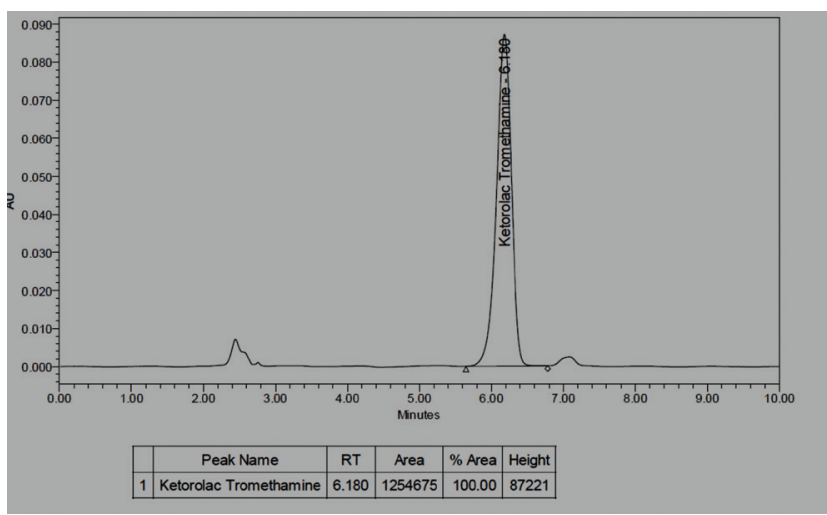

Figure 4: Estimation of Ketorolac Tromethamine (KT) in Serum by HPLC

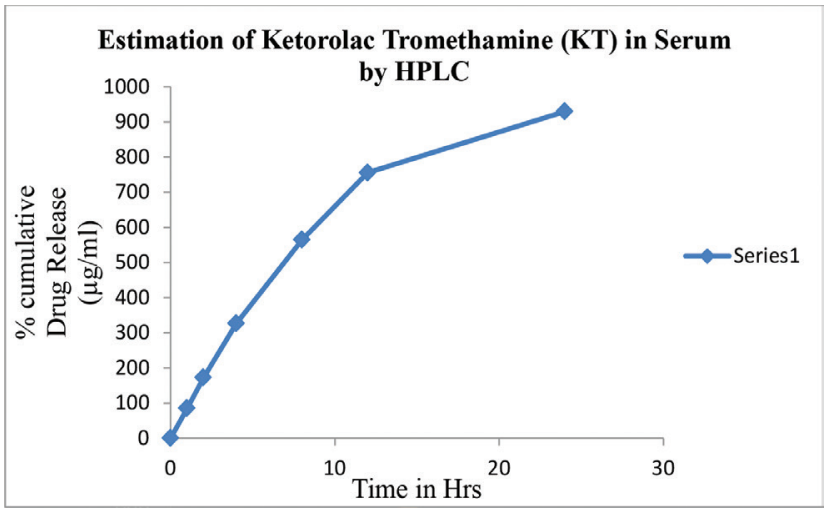

Figure 5: \% Cumulative Drug Release vs. Time Data in Serum

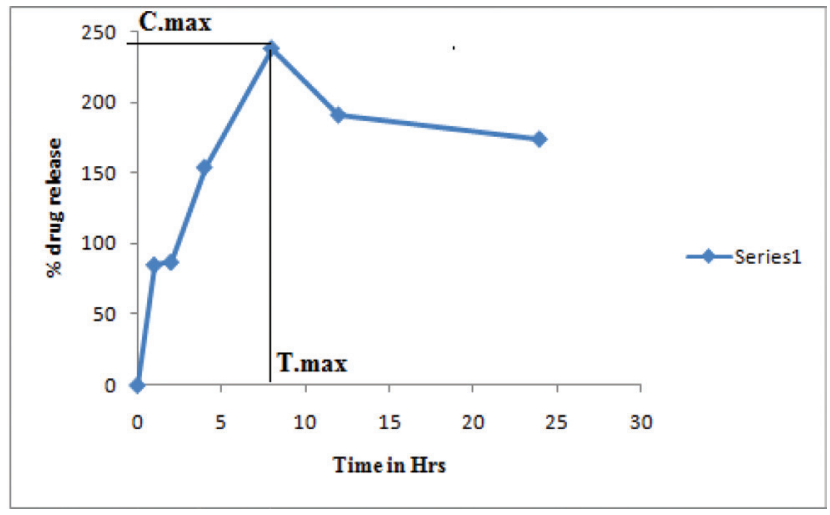

Figure 6: Estimation of $\mathrm{T}_{\text {max }_{\max }}$ andC $\mathrm{c}_{\max }$ in Serum

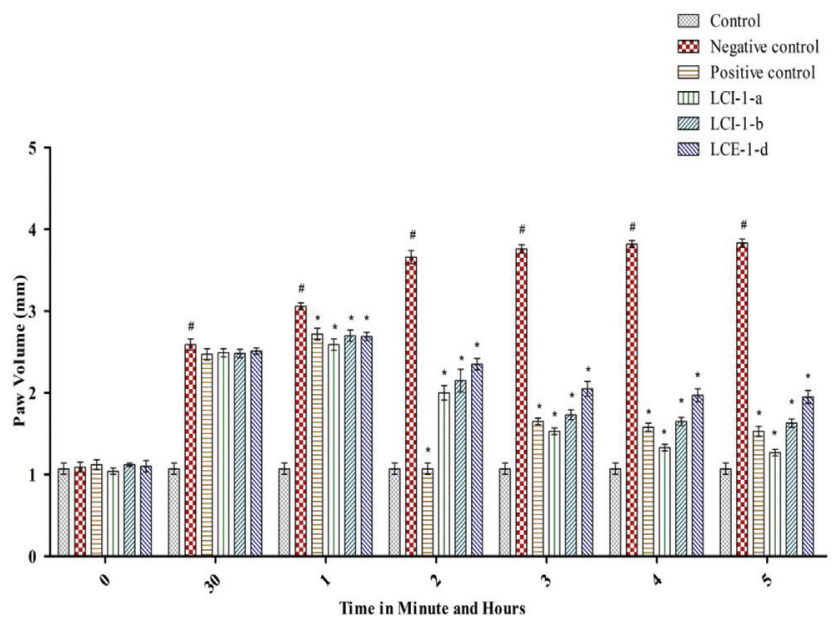

Figure 7: The Percentage Inhibition of Carrageenan Induced Paw Edema 5 Hours after Applying Formulations

formulation and ability to maintain the constant drug concentration over 24 hours. (Table 3 and Figure 4, 5\&6)

\section{Pharmacodynamic}

\section{Carrageenan Induced Rat Paw Edema}

The percentage inhibition of carrageenan induced paw edema, was observed after five hours applying the formulation F1 (LCI-1-a) gel and was found to be $66.84 \%$, which showed that formulation F1 gel containing proniosomal vesicles attained highest permeability in biological membrane along with prolonged release of drug as compare to other formulations while LCI1 -b and LCE-d gel formulations showed $57.44 \%$ and $49.08 \%$ inhibitions respectively. And marketed preparation (positive control) showed $60.00 \%$ inhibition,

The percentage inhibition shown after carrageenan induced Rat paw edema was found to be $60.00 \%$ for positive control, LCI-1-a gel was found to be $66.84 \%$ while LCI-1-b and LCE-d gel showed $57.44 \%$ and $49.08 \%$, respectively. (Figure 7) 


\section{CONCLUSION}

The result revealed that proniosomal gel (PN) of ketorolac tromethamine (KT) prolongs duration and therapeutic action of drug when compared with marketed gel preparation. KT is a water soluble drug candidate which shows poor bioavailability due to the low permeability on skin in conventional marketed gel formulation. This shows poor systemic bioavailability. On the other hand PN formulation of KT show significant improvement in bioavailability of $\mathrm{KT}$ in systemic circulation when applied via topical route, The observations reported that the bilayer lipid vesicle of proniosomes vesicles worked as permeability enhancers so it act like rate limiting in drug permeation, whereas sodium cholate and co-solvents (isopropanol) induced significant changes in membrane permeability. It completely solubilised membrane phospholipids by sodium cholate micelles and has shown a significant change in permeability in formulated batch F1 (LCI-a-1), as compared to the batches which contain sodium deoxy cholate and span- 60 . The obtained data established the sustained and prolonged delivery of ketorolac tromethamine from proniosomal gel formulation and ability to maintain the constant drug concentration in plasma over 24 hours as compared to conventional marketed formulation.

\section{ACKNOWLEDGMENT}

The authors are grateful to the Mr. Amitesh Pagare Piramal Health Care Pvt., Ltd. (Pithampur, India) for provided API, Institutional Animals Ethics Committee of Smriti College of Pharmaceutical Education (Indore, India) and Shail group of institution for the financial support and facilities to carry out this research work.

\section{CONFLICTS OF INTEREST}

The authors declare no conflict of interest.

\section{REFERENCES}

1. Robinson JR, Lee VH. Controlled Drug Delivery: Fundamentals and Applications, Marcel Dekker, New York. 1987: 523-552.

2. Daniels R, Knie U. Galenics of dermal products vehicles, properties and drug release. JDDG. 2007: 5: 367-381.
3. Bazigha K, Rasool A, Abu-Gharbieh EF, Fahmy SA Heyam SS, KhanSA Development and Evaluation of Ibuprofen Transdermal Gel Formulations. Tropical Journal of Pharmaceutical Research. August 2010: 9 (4): 355-363.

4. Jalwal P, Jangra A, Dahiya R. A review on transdermal patches. The Pharma Research 2010: 139-149.

5. Alsarra IA, Bosela A, Ahmed S, Mahrous G. Proniosomes as a drug carrier for transdermal delivery of ketorolac. Eur J Pharm Biopharm. 2004: 59(3): 485-90. DOI: 10.1016/j.ejpb.2004.09.006

6. Schreier H, Bouwstra J, Liposomes and niosomes as topical drug carriers: dermal and transdermal drug delivery. J Control Release. 1994: 30(1):1-15.

7. Sengodan T, Sunil B, Vaishali R, Chandra R.J. Formulation and evaluation of maltodextrin based proniosomes loaded with Indomethacin. Int J PharmTech Res. 2009: 1(3):517-23.

8. Ammar H, Ghorab M, El-Nahhas S, Higazy I. Proniosomes as a carrier system for transdermal delivery of tenoxicam. Int J Pharm. 2011: 405(1):14252. DOI: 10.1016/j.jpharm.2010.11.003.

9. Kumar $L$ and Verma R. In vitro evaluation of topical gel prepared using natural polymer. International Journal of Drug Delivery. 2010: 2: 58-63. DOI:10.5138/ijdd.2010.0975.0215.02012

10. Venkatesh DN, Priyank VS, Tulasi KT, Kalyani K, Sheik SA, Jilakara H. Proniosomes: A Superior Drug Delivery System. International Journal of Pharmaceutical Sciences and Drug Research. 2014: 6(3): 178-182. DOI. org/10.1155/2016/6492953

11. Cho YA, Gwak HS. "Transdermal delivery of ketorolac tromethamine: Effects of vehicles and penetration enhancers" Drug Devlnd Pharm. 2004: 30(6): 557-564.

12. Gupta A, Prajapati SK, Balamurugan M, Singh M, Bhatia D. Design and development of a proniosomal transdermal drug delivery system for captopril. Trop J Pharm Res. 2007:6(2):687-93.

13. Ibrahim MMA, Sammour OA, Hammad MA, Megrab NA. In vitro evaluation of proniosomes as a drug carrier for flurbiprofen. AAPS PharmSciTech. 2008:9(3):782-90. DOI: 10.1016/j.jsps.2014.05.001

14. Prajapati SK, Kumar S, Sahu VK, Prakash G. Proniosomal Gel of Flurbiprofen: Formulation and Evaluation. Journal of drug delivery \& Therapeutics. 2012:2-1.

15. Farooqui N, Kar M, Singh RP. "Formulation and Development of Proniosomal Gel for Transdermal Delivery of Ketorolac Tromethamine". Asian Journal of Pharmaceutics. Jul-Sep 2016: 10 (3): S394-400.

16. Dhiraj A, Khairnar Chetan S, Chaudhari and Sanjay P. Anantwar. "Method Development and Validation of Ketorolac Tromethamine in Tablet Formulation by RP-HPLC Method.” IJPSR, 2014: Vol. 5(9): 3696-3703. DOI: 10.13040/ IJPSR.0975-8232.5

17. Sunil G, Jambulingam M, Ananda S, Thangadurai D, Kamalakannan R, Sundaraganapathy C. Jothimanivannan. Development and validation of Ketorolac Tromethamine in eye drop formulation by RP-HPLC method. Arabian Journal of Chemistry. 2017: 10: S928-S935

18. Jain S, Garg VK, Sharma PK. "Anti-Inflammatory Activity of Aqueous Extract of Beta Vulgaris L." Journal of Basic and Clinical Pharmacy. May 2011: 2:83-86. DOI: 10.1155/2014/983952

19. Jain PS, Bari SB. Anti-inflammatory activity of Abelmoschusmanihot extracts. Int. J. Pharmacol. 2010: 6(4): 505-509.

20. Alam MI, Baboota S, Kohli K, Ali J, Ahuja A. Pharmacodynamic evaluation of proniosomal transdermal therapeutic gel containing celecoxib. Scienceasia. 2010: 36(1):305 -11.

21. Ibrahim MMA, Sammour OA, Hammad MA, Megrab NA. In vitro evaluation of proniosomes as a drug carrier for flurbiprofen. AAPS PharmSciTech, 2008: 9(3):782-90. 


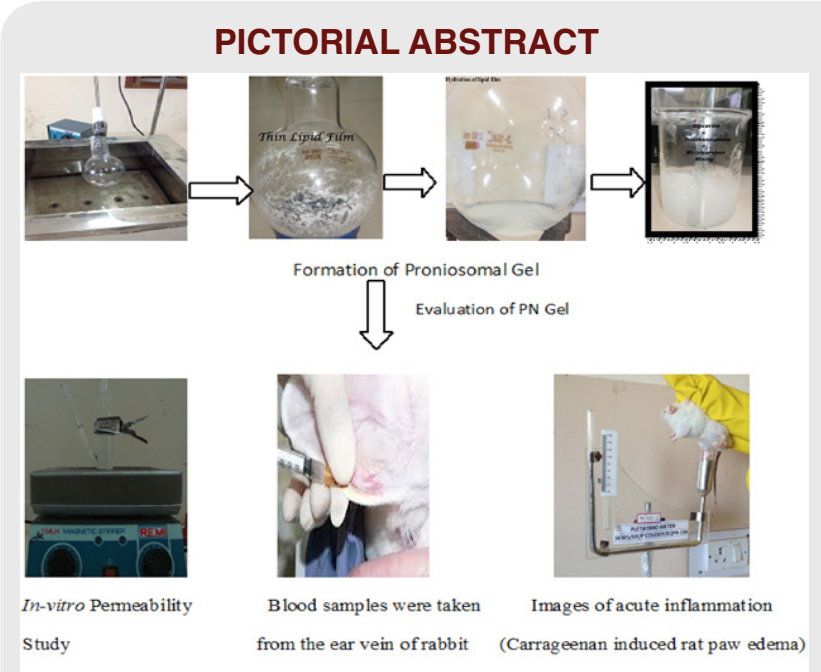

\section{SUMMARY}

- The proniosomal gel formulations were successfully prepared by rotatory evaporator method using cholesterol and sodium deoxycholate as surfactant.

- Serum estimation of Ketorolac Tromethamine (KT) in rabbit was performed by RP-HPLC and data revealed that application of optimized proniosomal gel formulation.

- These results established the sustained and prolonged delivery of Ketorolac Tromethamine from proniosomal gel formulation and ability to maintain the constant drug concentration over 24 hours.

\section{About Authors}

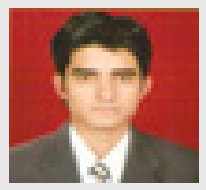

Nadeem Ahmed Farooqui: PhD research scholar with research interest in formulation development in pharmaceutical science.

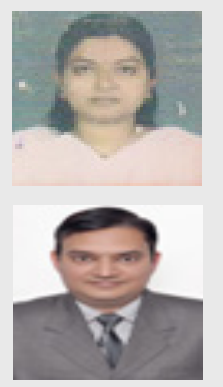

Dr Mousumi Kar: Academic researcher, with research interest in pharmaceutical science and in the development of novel drug delivery formulation.

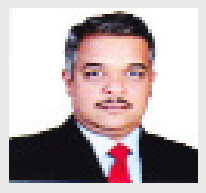

Dr Sanjay Jain: Academic researcher, with research interest in pharmaceutical science and stability studies of drug substances and documentation.

Cite this article: Farooqui NA, Kar M, Singh RP, Jain S. Development of Proniosomal Gel: in-vitro, ex-vivo and in-vivo Characterization. Indian J of Pharmaceutical Education and Research. 2017;51(4):758-64. 